\title{
Dating Violence and Help-Seeking Behaviour among Adolescent Undergraduates of Obafemi Awolowo University
}

\author{
Oluwatosin S. A. \\ Department of Educational Foundations and Counselling, \\ Obafemi Awolowo University, Ile-Ife, Nigerian. \\ Akinwale A. A. \\ Department of Educational Foundations and Counselling, \\ Obafemi Awolowo University, Ile-Ife, Nigerian.
}

\begin{abstract}
The study investigated dating violence and help-seeking behaviour among adolescent undergraduates of Obafemi Awolowo University. Using descriptive survey, an instrument, "Dating Violence and Help-Seeking Behaviour" was used to collect data from 591 students and data collected were analyzed using descriptive and inferential statistics. The study concluded that undergraduate adolescents experience dating violence and mostly in the form of emotional violence and they seek informal source of help which may account for under-reporting and hinder provision of appropriate formal source of help such as counselling intervention. It is recommended that school counsellors should try and sensitise the students about dating violence. University authorities need to implement strategies that encourage reporting of dating violence and ensure that reports are managed appropriately.
\end{abstract}

Keywords: Dating Violence, Help-Seeking Behaviour, Adolescents, Undergraduates, University

\section{INTRODUCTION}

Dating violence among adolescents is escalating rapidly and is a public health issue all over the world. The Michigan Department of Human Services (2001) has defined dating violence as a pattern of assaultive and controlling behaviours that one person uses against another in order to gain or maintain power in the relationship. The abuser intentionally behaves in ways that cause fear, degradation and humiliation in order to control the other person. Forms of this abuse can be physical, sexual, emotional or psychological. Dating violence happens to people of all races, cultures, income and education levels. It can happen to both young and old, and in heterosexual or same-sex relationship. Generally, adolescents experience the highest rates of dating violence in form of emotional violence. It can happen on a first date, or as the relationship progresses. Adolescents engage in heterosexual activities and relationship (such as dating relationship) due to their developmental and physiological responses.

Thus, adolescence is a period of life between childhood and adulthood. It is a developmental stage during which a growing individual makes the transition to adulthood. The period is characterized by psychological and social changes as well as biological. In fact, the biologist, sociologists and psychologists have different conceptualizations of the period of adolescence across culture. Though, the biological implication of the adolescence period seems to be widely accepted. The physical attributes of the adolescent during this period determine to a large extent some forms of the attendant problems, strains and stresses that individual encounters at this age (10-19years). As adolescents develop emotionally, they are heavily influenced by 
their relationship experiences. Healthy relationship behaviours can have a positive effect on a teenager's emotional development. Unhealthy, abusive or violent relationships can cause short term and long term negative effects, or consequences to the developing teenagers. Victims of teen dating violence are more likely to perform poorly in school, and report binge drinking, suicide attempts, and physical fighting. Victims may also carry the patterns of violence into future relationships. Adolescents receive messages about how to behave in relationships from peers, adults in their lives, and the media. However, Intimate Partner Violence (IPV) which is commonly referred to as Dating Violence among adolescents is a prevalent problem in some societies and has traditionally been thought of as a man physically aggressive against a woman (Hickman, 2001), it is now widely recognized that both men and women can be perpetrators and victims and that there are many forms of dating violence (i.e. physical, sexual, psychological/verbal). Violence is never acceptable. But there are reasons why it happens. Thus, the reason for dating violence cannot be overemphasized because violence is related to certain risk factors. Risks of having unhealthy relationships increase for adolescents who: believe it is okay to use threats or violence to get their way or to express frustration or anger, hang out with violent peers, have multiple sexual partners, have a friend involved in dating violence, are depressed or anxious, have learning difficulties and other problems at school, do not have parental supervision and support, witness violence at home or in the community and have a history of aggressive behaviour or bullying.

Dating relationships among adolescents are constructed in socio-cultural contexts through gender role socialization and cultural values (Pimlott-Kubiak, 2003). Though, successful dating can be a crucial ingredient in developing self-esteem and peer-group belonging; nonetheless the risks which adolescents could get involved in, especially when experiencing violence in dating relationship should not be overlooked. In adolescence, primary influence shifts from the family, which has been dominant since childhood, to peers. This change places adolescents at risk from much harmful behaviour owing to their increased sense of independence and susceptibility to peer pressure. Attitudes and beliefs about interpersonal relationships that form in adolescence are carried on later in life. In fact, violence in adult intimate relationships can often be traced to earlier manifestations in adolescent dating behaviour. However, being in an abusive relationship as an adolescent "is a risk factor for adult dating violence" and later in life, the abuse can become more serious. Hence, being a perpetrator or victim of dating violence does not mean an adolescent will become a victim or abuser later in life. "Given the right information and space, adolescents can make other choices in their relationships since they just begin to make their way in the world, have a sense for consequences, boundaries and figuring out their sexuality.

Meanwhile, seeking assistance of others has obvious instrumental benefits for the person in need; for example, it is likely to hasten the solution of one's problem. Help-seeking may lead to three categories of social support or help: (a) emotional support (concern, acceptance, understanding, or encouragement). This will go a long way in solving problems that arise in dating relationship; (b) information support (advice to aid problem-solving), information from adults knowledgeable about healthy dating relationship behaviour may improve the adolescent's understanding of a dating partner as a person and of the adolescent's role as a dating partner. Also, information received from help-givers may improve conflict negotiation and anger management skills; and (c) instrumental assistance (aid with tasks and contribution of material resources). Instrumental assistance may be vital for adolescents to ensure selfprotection, reduce the severity or frequency of violence and injuries, or obtain medical care.

Studies suggest that adolescents typically do not seek help for problems. The few that do, sex, age and family structure have been found to influence their help- seeking behaviours for 
problems such as family, interpersonal relationships, health, education, emotional, and mental health (Weidmr, 2007; Vogel, 2005). As adolescents mature, they develop the ability to generate hypotheses and predict outcomes to possible solutions which may or may not work out well. Some may even seek help from the wrong source which may worsen the case. It must be noted that there are two sources of help from which adolescents seek help; and these include informal and formal sources of help (Moore, 2006). Informal source of help includes friends, family and non-professionals while Formal source of help include doctors, nurse, psychologists and counsellors. There are some barriers to adolescents' help-seeking behaviour which include stigma attached to problems requiring help and to the associated help-seeking process, concerns about privacy, value placed on self sufficiency, poor knowledge of resources, low self-awareness related to the need for help, and an external locus of control. Nevertheless, there are many benefits of help- seeking to individual's wellbeing such as: getting support during tough times that helps to feel less stressed and relieved through sharing feelings, finding solutions and ways to cope, gain perspective, reduce ones sense of isolation and loneliness, building stronger relationships with family and friends, preventing problems from getting worse or leading to more serious issues and assisting others when they need it.

It could be noted that majority of male adolescents do express anger and aggression than female adolescents and will prefer seeking help from informal source of help even if they experience dating violence. Also, one's family structure such as monogamous or polygamous may determine the extent to which adolescents endorse dating violence and the source from which they see help from. Age may also be a determinant of dating violence and the victim's choice of helping source.In view of this, it is the concern of this study to investigate the forms and prevalence of dating violence among undergraduates in Obafemi Awolowo University, examine the patterns of help seeking behaviour of the victims, ascertain the influence of sex, age and family structure on the victims' choice of help and determine the counselling intervention strategies in managing dating violence. In developing countries, dating violence is prevalent among universities students' relationships, and dating violence being associated with negative outcomes, and in Nigeria, students experiencing or perpetrating dating violence are not properly denoted probably because of under-reporting of the incidence and for not seeking counselling. Therefore, understanding and promoting help-seeking behaviours of adolescents involved in dating violence is important for improving psychosocial and health outcomes. Moreover, identifying correlates of adolescent help-seeking in dating violence is important for developing interventions to reduce the incidence of dating violence among adolescents (White, 2001).

Dating Violence which consists of acts such as punching, strangling, name calling, forcing partner to have sex and unwanted touching and kissing can result into psychological trauma, injuries and even death for either the victim or the perpetrator (Straus \& Ramirez, 2004; Wolfe, 2001). Dating Violence has been found to be associated with a number of negative outcomes for male and female undergraduates such as higher rates of psychological distress (Harned, 2001; Kaura \& Lohman, 2007), depression (Gerlock, 1999), decreased relationship satisfaction, lower Grade Point Average (Bergman, 1992), absenteeism, interrupted studies, inability to concentrate on studies, loss of self confidence and higher academic withdrawal (Straus, 2008). According to Ikeola, Joseph and Olufunmilayo (2014), girls' and women's exposure to dating violence has been associated with increased morbidity and is documented as the third leading cause of mortality among women of reproductive age. This means that dating violence is a life-threatening problem primarily affecting women and men; and if care is not taken, it may go out of hand in future causing barrenness or death. Therefore, does sex influence adolescent's dating violence and help seeking behaviour? Does age affect adolescent's involvement in help-seeking for dating violence and does adolescent's family structure make 
them get involved in dating violence and seeking help from the right or wrong source? The need to provide answers to these questions motivated this study.

\section{Purpose of the Study}

The specific objectives of the study are to:

a. investigate the forms and prevalence of dating violence among undergraduate students in Obafemi Awolowo University;

b. examine the patterns of help-seeking behaviour of victims

c. ascertain the influence of sex, age and family structure on the victims' choice of help;

d. determine the counseling intervention strategies in managing dating violence.

\section{Research Questions}

In order to achieve the objectives of this study, three research questions were generated to be answered; these are:

1. What form of dating violence is relatively more prevalent among adolescent undergraduates of Obafemi Awolowo University?

2. Which help-seeking behaviour do adolescents demonstrate most?

3. What counselling intervention strategies would be appropriate for ameliorating dating violence among adolescent undergraduates?

\section{Research Hypothesis}

There is no significant influence of demographic variables (age and sex) on students' helpseeking behaviour

\section{Research Design}

\section{METHOD}

The study adopted survey research design. Based on the fact that all undergraduates cannot be possibly reached, the study was conducted using samples among adolescent undergraduates in the selected faculties and the result obtained from this are used to generalize for the entire population.

\section{Sample and Sampling Techniques}

According to statistics provided by the University Computer Centre, there were 23, 425 students in the University at the commencement of the 2013/2014 Harmattan semester. Sample for the study were therefore 591 students, representing $2.5 \%$ of the population from Obafemi Awolowo University. The sample comprised 274 males and 317 females between the age range of 10 and 19. The sample was selected using snowball sampling technique. First, five faculties were selected from the 13 faculties in the university using simple random sampling technique (balloting system). Three departments were randomly selected from each of the selected faculties which gave a total of 15 departments. Forty students were selected from each department using snowball sampling technique.

\section{Research Instrument}

An instrument tagged "Dating Violence and Help-seeking Behaviour" (DVHSB) was used to collect data for the study. The validity of the instrument was ascertained by two lecturers in the department of Educational Foundations and Counselling (both Tests and Measurement and Guidance and Counselling).

The questionnaire was made of five sections. Section A contains items on demographic variables such as: age, sex, religion, family structure and recent state of the family. Section B contained 40 items on patterns of adolescents' dating violence; Section C contained one item 
on the forms of dating violence. Section D contained 11 items on help seeking behaviour for dating violence while Section E contained one item the counselling strategies in managing dating violence.The instrument has 53 items spread across patterns of dating violence, forms of dating violence, help-seeking behaviour and the counselling strategies in managing dating violence. Some of the items in the instrument was structured along "Strongly Agree (SA), Agree (A), Disagree (D) to Strongly Disagree (SD)" response pattern, others provided many options from which the respondents picked their choices.

\section{Data Collection}

The Researcher started by going to a class immediately the lecturer in each of the selected classes or departments left so as to meet a good number of students in the class on which to administer the questionnaire. In some of the classes, the researcher found out from some of the students to know who has experienced dating violence; the researcher then gave the questionnaire to the first student who indicated that he has experienced it; the student pointed to another student who was also experiencing it. This continued until the number assigned for each department was reached. The researcher then distributed the questionnaire to the students, giving them enough time to fill and assured the respondents that their responses shall be treated with utmost confidentiality. To aid the level of confidentiality, the researcher asked the respondents not to put their names on the questionnaire. Six hundred copies of the questionnaire were administered, out of which the researcher retrieved five hundred and ninety-five copies of the questionnaires from the field. Four of them were rejected because they were not properly filled and some of the pages were torn either by the respondents or at the point of collection. Five hundred and ninety-one copies of the questionnaires were then found useful. The data collection process lasted four weeks.

\section{Data Analysis}

The data collected were analyzed using t-test, chi-square, simple percentage and frequency counts to answer the three research questions generated for the study.

\section{RESULTS}

Research Question 1: What are the forms and prevalence of dating violence experienced by undergraduates of Obafemi Awolowo University?

To determine the prevalence of dating violence, the students' responses to section B of the questionnaire was subjected to Factor Analysis. The result is as follows:

Table 1: Forms of Dating Violence among the Adolescents.

\begin{tabular}{|c|l|l|}
\hline Factor & \multicolumn{1}{|c|}{ Items } & \\
\hline 1 & $22,23,24,25,26,27,28,29,30$ & $\begin{array}{l}\text { Socio-Psychological } \\
\text { aggression }\end{array}$ \\
\hline 2 & $16,18,20,21$ & Emotional abuse \\
\hline 3 & $1,2,3,4,5,6,7,8,9$ & Physical abuse \\
\hline 4 & $9,10,11,12,13,14,15,16,17,18,19$ & Socio-emotional abuse \\
\hline 5 & $31,35,36,37,38,39,40$ & Sexual abuse \\
\hline
\end{tabular}

It can be seen from the table that five factors were extracted and the forms of dating violence experienced by the respondents were identified. In order to determine the form of dating violence experienced by each of the respondents, the constituting items under each factor (form) was summed up and further subjected to cluster analysis. A student is identified with any particular form of dating violence where he/she had the highest rating. The summary of the result is presented in Table 2 . 
Table 2: Major Forms of Dating Violence among Adolescents.

\begin{tabular}{|l|c|c|}
\hline & Frequency (F) & Percentage (\%) \\
\hline Physical Abuse & 51 & 8.6 \\
\hline Sexual Abuse & 117 & 19.8 \\
\hline Emotional Abuse & 423 & 71.6 \\
\hline Total & 591 & 100.0 \\
\hline
\end{tabular}

From Table 2 above, through the method of cluster analysis, it was shown that $51(8.6 \%)$ experienced Physical Abuse, 117(19.8\%) experienced Sexual Abuse while 423(71.6\%) experienced Emotional Abuse. This implies that Emotional Abuse is more prevalent among adolescents in Obafemi Awolowo University Ile-Ife than other forms of dating violence identified among them.

Table 3: Socio-Demographic Information of the Adolescents experiencing dating violence

\begin{tabular}{|c|c|c|c|}
\hline Variable & Levels & Frequency & Percentage (\%) \\
\hline \multirow{4}{*}{ Age } & $14-15$ & 19 & 3.2 \\
\cline { 2 - 4 } & $16-17$ & 185 & 31.3 \\
\cline { 2 - 4 } & $18-19$ & 387 & 65.5 \\
\cline { 2 - 4 } & Total & 591 & 100.0 \\
\hline \multirow{3}{*}{ Sex } & Male & 274 & 46.4 \\
\cline { 2 - 4 } & Female & 317 & 53.6 \\
\cline { 2 - 4 } & Total & 591 & 100.0 \\
\hline
\end{tabular}

Furthermore, to expatiate more on the research question, the students' responses were also treated to a descriptive analysis to present a general view of dating violence those students experience. The result is shown in table 4 above.

Research Question 2: What are the counselling strategies that adolescents prefer in managing dating violence?

Table 4: The Counselling Strategies for Managing Dating Violence

\begin{tabular}{|l|c|c|}
\hline & Frequency (F) & Percentage (\%) \\
\hline Assertiveness Training & 246 & 41.6 \\
\hline Creating a Safety Plan & 182 & 30.8 \\
\hline Suggesting legal options & 163 & 27.6 \\
\hline Total & 591 & 100 \\
\hline
\end{tabular}

To answer this research Question, the Section E of the questionnaire was given a descriptive analysis and the result is presented in Table 4.

Table 4 revealed the counselling strategies preferred by adolescents in managing Dating Violence. It was reported that $246(41.6 \%)$ of the adolescents preferred Assertive Training, 182(30.8\%) preferred Creating Safety Plan while 163(27.6\%) preferred Suggesting Legal Options. There is an indication from the result that majority of adolescents preferred Assertiveness Training.

Research Question 3: Which of formal and informal help-seeking do adolescents demonstrate more frequently? 
To answer this question, the items in the sections on formal and informal help seeking efforts were scored as pre-stated, the constituting items were summed up and the resulting scores were compared. Respondents are said to demonstrate more frequently the type of help seeking in which s/he scores highest. The summary is shown in table 5, 6 and 7

The Help-Seeking Approaches Adolescents Adopt when they Experience Dating Violence.

Table 5: Informal Source of Help-Seeking Behaviour of the Adolescents

\begin{tabular}{|c|c|c|c|c|c|c|c|c|c|}
\hline & \multirow[t]{2}{*}{ STATEMENTS } & \multicolumn{2}{|c|}{$\begin{array}{l}\text { Strongly } \\
\text { Agreed }\end{array}$} & \multicolumn{2}{|c|}{ Agreed } & \multicolumn{2}{|c|}{ Disagreed } & \multicolumn{2}{|c|}{$\begin{array}{c}\text { Strongly } \\
\text { Disagreed }\end{array}$} \\
\hline & & $\mathrm{F}$ & $\%$ & $\mathrm{~F}$ & $\%$ & $\mathrm{~F}$ & $\%$ & $\mathrm{~F}$ & $\%$ \\
\hline 1. & $\begin{array}{l}\text { I would talk to a friend to help } \\
\text { resolve the conflict. }\end{array}$ & 79 & 13.4 & 135 & 22.8 & 219 & 37.1 & 158 & 26.7 \\
\hline 2. & $\begin{array}{l}\text { I prefer discussing any dating } \\
\text { violence experience with my parent }\end{array}$ & 112 & 19.0 & 156 & 26.4 & 157 & 26.6 & 165 & 27.9 \\
\hline 3. & $\begin{array}{l}\text { My relatives would be the best } \\
\text { source to seek help from }\end{array}$ & 92 & 15.6 & 185 & 31.3 & 129 & 21.8 & 185 & 31.3 \\
\hline 4. & $\begin{array}{l}\text { I think it is better for me to disclose } \\
\text { the issue and seek help on the } \\
\text { internet(on-line conversation) } \\
\text { hiding my identity }\end{array}$ & 97 & 16.4 & 135 & 22.8 & 158 & 26.7 & 200 & 33.8 \\
\hline 5. & $\begin{array}{l}\text { I would take decision based on my } \\
\text { own opinion }\end{array}$ & 131 & 22.2 & 131 & 22.2 & 139 & 23.5 & 190 & 32.1 \\
\hline
\end{tabular}

Table 5 shows the responses of the students about the informal source of help they prefer to seek in managing dating violence. It can be seen from the table that most of the adolescent undergraduates would take decision on their own opinion in managing dating violence.

Table 6: Formal Source of Help-Seeking Behaviour of the Adolescents

\begin{tabular}{|l|l|c|c|c|c|c|c|c|c|}
\hline & & \multicolumn{2}{|c|}{$\begin{array}{l}\text { Strongly } \\
\text { Agreed }\end{array}$} & \multicolumn{2}{c|}{ Agreed } & \multicolumn{2}{c|}{ Disagreed } & \multicolumn{2}{c|}{$\begin{array}{l}\text { Strongly } \\
\text { Disagreed }\end{array}$} \\
\hline & & F & \% & F & $\%$ & F & $\%$ & F & $\%$ \\
\hline 6. & $\begin{array}{l}\text { I would talk to someone I } \\
\text { trust on campus (e.g., a } \\
\text { professor, advisor, coach, } \\
\text { lecturer, porter) to learn } \\
\text { more about what to do. }\end{array}$ & 145 & 24.5 & 169 & 28.5 & 147 & 24.9 & 135 & 22.8 \\
\hline 7. & I would call the police. & 110 & 18.6 & 131 & 22.2 & 129 & 21.8 & 221 & 37.4 \\
\hline 8. & $\begin{array}{l}\text { I would talk to health } \\
\text { services to learn more } \\
\text { about what to do. }\end{array}$ & 115 & 19.5 & 167 & 28.3 & 127 & 21.5 & 182 & 30.8 \\
\hline 9. & $\begin{array}{l}\text { I would go to a doctor or } \\
\text { general practitioner. }\end{array}$ & 123 & 20.8 & 176 & 29.8 & 136 & 23.0 & 156 & 26.4 \\
\hline 10. & $\begin{array}{l}\text { I would prefer to discuss } \\
\text { it with a counsellor } \\
\text { (school counsellor or } \\
\text { counselling centre) }\end{array}$ & 139 & 23.5 & 173 & 29.3 & 130 & 22.0 & 143 & 24.2 \\
\hline 11. & $\begin{array}{l}\text { I would rather sue the } \\
\text { perpetrator to court or } \\
\text { invite a lawyer to } \\
\text { intervene }\end{array}$ & 84 & 14.2 & 121 & 20.5 & 159 & 26.9 & 227 & 38.4 \\
\hline
\end{tabular}


Table 7: Informal and Formal Source of Help-Seeking

\begin{tabular}{|l|c|c|}
\hline & Frequency(F) & Percentage (\%) \\
\hline Formal & 265 & 44.8 \\
\hline Informal & 326 & 55.2 \\
\hline Total & 591 & 100.0 \\
\hline
\end{tabular}

Table 7 revealed that 265(44.8\%) adolescents demonstrated formal help-seeking behaviour while 326(55.2\%) demonstrated informal help-seeking behaviour. This implies that larger percentage of adolescents employ informal help-seeking behaviour whenever they are faced with dating violence.

Hypothesis 1: There is no significant influence of sex on adolescents' help seeking behaviour for dating violence.

To test this hypothesis, the students' sex was cross-tabulated with the students' help seeking behaviour for dating violence. The t-test statistic was also obtained and a Yates continuity correction analysis was also undertaken as presented in Table 12.

Table 8: Influence of sex on adolescents' help seeking behaviour for dating violence

\begin{tabular}{|c|c|c|c|c|c|c|c|c|c|}
\hline & \multicolumn{2}{|c|}{ HSB } & \multirow{2}{*}{ Total } & \multicolumn{3}{|c|}{ t test } & \multicolumn{3}{|c|}{$\begin{array}{l}\text { Yates Continuity } \\
\text { correction }\end{array}$} \\
\hline Sex & Informal & Formal & & $\mathrm{T}$ & Df & $\mathrm{P}$ & $\mathrm{T}$ & Df & $P$ \\
\hline Female & $174(54.9 \%)$ & $143(45.1 \%)$ & $317(100.0 \%)$ & \multirow{3}{*}{.144} & \multirow{3}{*}{1} & \multirow{3}{*}{0.000} & \multirow{3}{*}{11.720} & \multirow{3}{*}{1} & \multirow{3}{*}{.001} \\
\hline Male & $152(55.5 \%)$ & $122(44.5 \%)$ & $274(100.0 \%)$ & & & & & & \\
\hline Total & $326(55.2 \%)$ & $265(44.8 \%)$ & $591(100.0 \%)$ & & & & & & \\
\hline
\end{tabular}

Table 8 shows the influence of the sex of the respondents and the help seeking behaviour they adopt in times of dating violence. It can be seen from the table that t-test statistic obtained in the test was $(11.720$, at $p=0.005)$ and since the $p$-value fails to attain the 0.05 threshold, the hypothesis cannot be accepted. Even when the Yates continuity correction was applied, the ttest statistic obtained was 11.720 at $p=0.001$ such that the $p$-values still fails to attain the 0.05 threshold. It can therefore be concluded that there is a significant influence of the students' sex on the informal and formal help seeking behaviour they adopt in times of dating violence.

Hypothesis 2: There is no significant influence of age on adolescents' help seeking behaviour for dating violence

To test this hypothesis, the students' age was cross-tabulated with their help-seeking behaviour in times of dating violence. The t-test statistic was also obtained and the result of the analysis is presented in Table 9.

Table 9: Influence of age on adolescents' help-seeking behaviour for dating violence

\begin{tabular}{|l|c|c|c|c|c|c|}
\hline \multirow{2}{*}{ Age } & \multicolumn{2}{|c|}{ HSB } & \multirow{2}{*}{ Total } & \multicolumn{3}{c|}{ Chi Square test } \\
\cline { 2 - 3 } & Informal & Formal & & $\chi^{2}$ & $\mathrm{df}$ & $\mathrm{P}$ \\
\hline 14 to $15 \mathrm{yrs}$ & 12 & 7 & 19 & & & \\
\hline 16 to $17 \mathrm{yrs}$ & 89 & 96 & 185 & \multirow{2}{*}{4.325} & 2 & .115 \\
\hline 18 to $19 \mathrm{yrs}$ & 164 & 223 & 387 & & & \\
\hline Total & 265 & 326 & 591 & & & \\
\hline
\end{tabular}


Table 9 shows the relationship between the age of the respondents and the help seeking behaviour they adopt in times of dating violence. It can be seen from the table that chi-square statistic obtained in the test was 4.325 at $\mathrm{p}=0.115\left(\mathrm{x}^{2}=4.325, \mathrm{p}>.05\right)$ and since the $\mathrm{p}$-value is greater than the 0.05 threshold, the hypothesis can therefore be accepted. It can therefore be concluded that there is no significant relationship between the students' ages and the help seeking behaviour they adopt in times of dating violence.

\section{DISCUSSION}

The primary goal of this study was to determine the prevalence of dating valence and the help seeking behaviour of adolescent undergraduates experiencing it and to ascertain if some demographical factors (age and sex) could influence students' help-seeking behaviour for dating violence. One of these findings showed that most of the undergraduates in Obafemi Awolowo University experienced dating violence; and this shows that the prevalence of dating violence in the institution is high. What could have accounted for this high prevalence rate of dating violence among adolescents could be the nature of adolescence stage, family background or environment in which they are brought up. At adolescence stage, there is a high tendency of experimenting diverse risky behaviour which may lure the adolescents into violence in their relationship. Many adolescents who were brought up in a hostile family or environment especially university where violence is rampart, may not see anything bad in experiencing violence in relationship (they tend to accept violence as the norm).

Emotional, physical and sexual victimization are serious problems affecting young women in high school and college. This finding corroborates the finding of Hickman and Shook who found out that Psychological/Emotional Dating Violence, which includes hurtful comments to a partner, is perpetrated by young women and young men (Hickman, 2004; Shook, 2000). Emotional form of violence may be very germane because it is hardly noticed by a third party and this cannot be repeated easily. Also, because students are not allowed by regulation to fight or engage in physical combat, they may result to emotional abuse to settle their differences. It often starts with threatening to hit or throw something at one's partner(emotional abuse) and may eventually lead to throwing something at the partner; pushing, grabbing, pinching; hitting or attempting to hit one's partner with a hand, fist or something hard(physical abuse). However, the prevalence of physical violence obtained was lower than what was reported by White and Koss (2001). It was observed in this study that girls inflict more physical violence than boys; though some females use violence at times as self-defense or in response to male physical violence. Most of the time, females prefer verbal confrontation (emotional abuse) or talking to the senses of their partners. But in the case of the males; most of them prefer different forms of physical abuse like hitting and giving their partners scars when they are annoyed.

In terms of how helpful adolescents thought the various sources of help would be, they reported the informal sources of help as most helpful, especially parents. The percentage of adolescents who reported that formal source of help such as police, lawyers, counsellors, or teachers at school would be quite a bit or extremely helpful was somewhat lower, while adolescents rated friends, family and other informal sources of help were of higher percentage. Fewer than half of participants thought that a doctor or other health professional, or school nurse could be quite a bit or extremely helpful to them. Thus, adolescents ranked sources of support as more helpful than they reported that they would likely to seek help from them, indicating some possible reluctance to seek help for problems related to dating violence. This instigates that adolescents are aware of sources of help but will not seek help maybe because of cultural or personal reasons inhibiting the disclosure of such events. Even if they want to seek help, they may hesitate to seek help from professionals for fear of retaliation or 
embarrassment; fear of being stigmatized and self-blame. Some may not even know how or where to get help from after being violated. Several of the students also reported that they would seek help from family members or friends. This is consistent with African traditional norms that consider intimate relationship as family issue and not an individual affair. It must be noted that even with friends, they have to be careful about whom they confide in; due to the fact that people might divulge sensitive information that could embarrass them or even make an abusive situation worse. Some students preferred to talk to their parents especially their mothers. Still other students worried that their parents would get upset or mad at them or blow things out of proportion and that they would lose control over the situation by confiding in their parents. It must be noted that professional help is trusted if young people know what trust in people in general means; and if they are aware of their feelings and can handle or communicate them. Professional help needs to be publicized, and made more accessible to everyone and everywhere when needed. More so, professional help and reliable information about it should be more readily accessible in schools and other settings for the young people.

It was also indicated by most of the respondents that they would prefer assertiveness training to creating a safety plan and suggesting legal options. Through assertiveness training, adolescent undergraduates will be taught how to be self-assured and confident without being aggressive. Also, they will be taught how to Say "No" and develop the ability to resist or sidestep being manoeuvred into doing something they do not really want to do; without actually using the word. Many adolescents have a real problem with having to tell other people they cannot do something. Of course, there will always be times when saying no is absolutely necessary. But there may be so much anxiety about the consequences of saying no; in fact, unassertive people just do not say no. They either say nothing at all, or agree to things they do not want to, or end up in mess. Thus, it is necessary for counsellors to start assertiveness training even in Obafemi Awolowo University and other institutions to assist the students and schools in controlling the prevalence of dating violence. This will go a long way in teaching victims of dating violence to clearly communicate what they want and also stand up for their rights.

Another finding of this study is that more female students seek for formal source of help than the males do. Thus, it found a significant influence of sex on help-seeking behaviour of the students (both formal and informal). One can deduce from the analysis that female students are easily prone to dating violence (being victimized) because they are more flexible and always put all their trust, mind and lives in any relationship they are involved in than male students; and also seek help from other sources than males and even formal source of help. It is therefore noteworthy that sex stands out of the independent variables tested. Sex had the strongest influence on students' help seeking behaviour of all the demographical factors that were tested in this research. Boys and girls were similar in their report of help seeking, with the exception that more girls than boys reported that they would talk to counsellors, teachers and health practitioners (formal source of help) about the situation. Females are more emotional and usually the victim, powerless and culturally submitted to males, or weak to defend themselves. It is in contrast with masculinity for male to keep things to themselves and consider it as a sign of weakness to report to others, what they have suffered from ladies not to talk of seeking help. This might account for the difference in help seeking with regard to sex. About half of participants said they would try to stop the situation on their own. Some sex differences were apparent, with girls rating school nurses, police officers, counsellors and lawyers as more helpful than boys rated them. That is, males reported that they prefer seeking help from informal source such as friend, family, internet and other informal source of help while more of the females reported that they prefer seeking help from formal source like counsellors, health professionals, teachers and other formal source of help. 
Another reason why boys would not seek much of formal source of help might also be that they needed to feel close to and trust the person they told, and believe that the person understood them and care for them. Also, the male students who would have reported the case of their relationship violence to their teachers; but because they feared that the teachers would report the abuse to counsellors, their family, or other school staff and that the situation would escalate beyond their control (fear of stigma also relates to fears regarding the confidentiality of professional services); they rather go to friends or internet to seek help. Also, many of the students might have very negative perception of law enforcement officials; that they do not trust them, and felt that the police and other law enforcement or emergency service personnel do not care about them. The students also seemed to feel that the police would not take their complaint seriously because they are just adolescents and stated that unless they had physical evidence that indicated that they had been abused, the police were unlikely to do anything about it. When examining the survey responses from the students' survey in terms of actual help sought, the percentages of adolescents who sought help related to violence out of the entire sample were examined. The percentage of those who seek help from informal sources most often (friends, parents, siblings, and other relatives) is more than those who seek help from formal sources of support. To this effect, a word of encouragement from teachers and counsellors who must have understood the pros and cons of dating violence to their students; goes a long way in facilitating the magic and wonders of saving the students who are victims from its (dating violence) trauma and even to prevent it. Also, the teachers are encouraged to get closer to their students, care for them, know and understand them.

Another major finding of this study was the hypothesis tested that there was no significant influence of age on the help-seeking behaviour of the students. The results showed that age had no significant influence on students' help seeking behaviour. From this finding, one can deduce that irrespective of the age of the student or how exposed he or she is; to life beyond his or her family. He or she could seek help from the only source, comfort zone or a place of convenience which he/she thinks can proffer solution to his or her problem. This connotes that no matter how old or young the student is, it does not make any difference in the decision made on which source to seek help from. This indicates that the age could not influence the help seeking behaviour of undergraduates which in turn could either mar or make his or her academic performance. An example of how study variability leads to seemingly discrepant findings is the association between age and DV perpetration found by Cyr, McDuff, and Wright (2006) compared to Moore, Elkins, McNulty, Kivisto, and Handsel (2011). Cyr found a positive relationship between age and DV, while Moore found the opposite. The variability in these findings is likely due to the age differences between study samples. Participants in the Cyr's study were between the ages of 13 and 17, whereas the participants in Moore's study were 18 years old or older. Meanwhile, this study agrees with the findings of Moore but in contrast with the findings of Cyr. It also agrees with Lamm, 2010 who found out that dating violence is a significant issue affecting today's youths, regardless of age, ethnicity, intelligence, and socioeconomic status. The motive of seeking help depends on the person's view about help seeking and not on the age of the student. Hence, rates of DV perpetration and victimization generally peak in young adulthood, which would be consistent with both study findings. Thus, the equivocal nature of the findings can be attributed both to inconsistency in measurement and methodology.

Thus, efforts to prevent dating violence should commence early when individuals are of school age and before behaviours become fixed. Also, acts of emotional, sexual and physical violence should not be tolerated and should be punished among young people. The society should not blame victims believing they have called for the experience or they should not be in relationship. 


\section{CONCLUSION AND RECOMMENDATIONS}

This study indicated that dating violence is greatly pronounced among adolescents due to the fact that adolescence is a particularly risky time for dating violence and most victims experience it (dating violence) majorly in form of emotional abuse. Thus, those who sought help for dating violence chose friends and family members which are known as informal source rather than professionals which are known as formal source. However, this may be the reason for under-reporting and delay in provision of formal source; such as counselling intervention. The study also concluded that sex could enhance undergraduate students' experience of dating violence and help-seeking behaviour. This is because, female victims who sought help especially formal source of help were more than male victims who chose formal sources of help.

On the basis of the findings of this study, these recommendations are given as subsequently as thus:

1. All young people have the right to be safe in their relationships. Dating violence affects young people in a unique way and can have long-lasting negative physical and psychological consequences. Providing young people with the communication and conflict resolution skills, support, and resources to avoid or end unhealthy and violent relationships is a key to their well-being. Meanwhile, underlying causes such as poverty, and violence as a social norm, must be addressed in order to bring an end to relationship violence.

2. All students should receive education about healthy relationships in as a part of health education. These lessons should include understanding and identifying healthy and unhealthy relationship patterns; effective ways to communicate relationship needs and manage conflict; and strategies to avoid or end an unhealthy relationship. Education could provide each partner with the knowledge and skills needed to improve his or her assertiveness in a relationship thereby decreasing his or her likelihood of experiencing dating violence.

3. Interventions targeting perpetration and victimization of intimate partner violence among adolescents can be effective. Those interventions are more likely to be based in multiple settings, and focus on key people in the adolescents' environment.

4. Since physical violence often arises during conflict, multi- prolonged interventions that target youth experiencing physical dating violence should address communication and conflict resolution skills within relationships.

5. Dating violence occurs within relationships and needs to be addressed in that context. Anti-violence campaigns and education should acknowledge how unhealthy intimate partner dynamics might result in violence and provide young people with the tools to navigate conflict effectively and avoid violent behaviour. Campaigns that simply condemn perpetrators of violence are less effective.

6. Adolescent clinics can serve as a critical site for identifying adolescent dating violence, and for offering resources, referrals, and otherwise intervening to assist young women in danger. Experiencing dating violence may result in particular health concerns that affect care-seeking patterns, such as need for pregnancy testing or sexually transmitted infection treatment.

7. While health care professionals should not assume that patients will disclose abuse, even when asked directly, they should make information about dating violence hotlines and assistance for assault patients available to all visitors. School Counsellors should try and sensitise the students about dating violence. University authorities need to implement strategies that encourage reporting of dating violence and ensure that reports are managed appropriately. There is, therefore, need to encourage both adolescents to identify and establish such protective relationships, and professionals to 
reach out to adolescents to facilitate the building of such relationships. In the nutshell, professional help-seeking services need to be taken to adolescents; help needs to be very easy to access, in fact, put in their pathway, as young people will not go out of their way to seek professional help themselves.

8. Teachers and parents should also act as guidance to students through proper monitoring and care with listening ears.

\section{References}

Alberti, R, and M, Emmons (2001). Your Perfect Right: Assertiveness and Equality in Your Life and Relationships. Atascadero, CA: Impact Publishers, 180-187

Allport, G. \& Ross, J.M. (1967).Personal religious orientation and prejudice.Journal of Personality and Social Psychology, 5, 432-443.

Anderson, K. L. (2005). Theorizing gender in intimate partner violence research.Sex Roles, 52, 853-865.

Archer, J. (2000). Sex differences in aggression between heterosexual partners: A meta-analytic review. Psychological Bulletin, 126, 651-680.doi:10.1037/0033-2909.126.5.651

Baker, C. R., StithS. M.(2008).Factors predicting dating violence perpetration among male and female college students. Journal of Aggression, Maltreatment \& Trauma, 17, 227-244. doi:10.1080/10926770802344836

Bandura, A. (1977) Social learning theory. Englewood Cliffs, NJ: Prentice-Hall. 78-87

Bell, K.M., \&Naugle, A.E. (2008). Intimate partner violence theoretical considerations: Moving towards a contextual framework. Clinical Psychology Review, 28, 1096-1107.

Ben-David, S., \& Schneider, O. (2005). Rape perceptions, gender role attitudes, and victim-perpetrator acquaintance.Sex Roles, 53, 385-399.168

Black, B., \&Weisz, A. (2003). Dating violence: Help-seeking behaviors of African American middleschoolers. Violence Against Women, 9, 187-206.Boladale, M. (2015).PersonalityProfiles and Psychopathology among students exposed to dating violence: Journal Interpersonal Violence.

Brown, C. (2008). Gender-role implications on same-sex intimate partner abuse. Journal of Family Violence, 23, 457-462. doi:10.1016/j.cpr.2008.03.003

Boivin, S., Lavoie F., Hebert M., Gagne M.-H.(2012). Past victimizations and dating violence perpetration in adolescence: The mediating role of emotional distress and hostility. Journal of Interpersonal Violence, 27, 662-684. doi:10.1177/0886260511423245 Bookwala, J.,Frieze I.H

Carlson, L. A. (2003). Existential theory: Helping school counselors attend to youth at risk for violence. Professional School Counselling, 6, 310-315.

Chimaraoke, O. I., Emmanuel J. C., Peter O. D. (2015) Women and Male Partner-dating violence in Nigeria. Journal of interpersonal violence.ijg. Sage publication.com.

Coker, A.L., Davis, K.E., Arias, I., Desai, S., Sanderson, M., Brandt, H.M., Smith, P.H. (2002). Physical and mental health effects of intimate partner violence for men and women.American Journal of Preventive Medicine, 23, 260268.

Crooks, C.V., Goodall, G.R., Hughes, R., Jaffe, P.G., \& Baker.L.L. (2007). Engaging men and boys in preventing violence against women: Applying a cognitive behavioural model. Violence Against Women, 13(3), 217-239.

Deurzen, E., van (1997). Everyday Mysteries: Existential dimensions of psychotherapy. Routledge.

Du Plock(2010). Trauma in the Relational World: An Existential Perspective. British Psychological Society, Division of Counselling Psychology Conference: Approaching Trauma. Attended 17th April 2010

Fass, D.F., Benson, R.I., \& Leggett, D.G. (2008). Assessing prevalence and awareness of violent behaviors in the intimate partner relationships of college students using internet sampling.Journal of College Student Psychotherapy, 22(4), 66-75.

Fincham, F.D., Cui, M., Braithwaite, S., \&Pasley, K. (2008). Attitudes toward intimate partner violence in dating relationships. Psychological Assessment, 20(3), 260-269.

Follingstad, D.R., DeHart, D.D., \& Green, E.P. (2004). Psychologists' judgments of psychologically aggressive actions when perpetrated by a husband versus a wife.Violence and Victims, 19, 435-452. 
Foshee, V. A., Linder, G. F., Bauman, K. E., Langwick, S. A., Arriaga, X. B., Heath, J. L., (1996). The Safe Dates Project: Theoretical basis, evaluation design, and selected baseline findings. American Journal of Preventive Medicine, 12, 39-47.

Goodman, L. A., Dutton, M. A., Weinfurt, K., \& Cook, S. (2003). The Intimate Partner Violence Strategies Index: Development and application. Violence Against Women, 9(2), 163-186.

Hamel, J. (2006). Domestic violence: A gender-inclusive conception. In J. Hamel \& T. Nicholls (Eds.) Family Approaches to Domestic Violence: A Guide to Gender - Inclusive Research and Treatment (pp. 3-26). New York, NY: Springer Publishing.

Harned, M.S. (2002). A multivariate analysis of risk markers for dating violence victimization.Journal of Interpersonal Violence, 17, 1179-1197.

Hickman, L., Jaycox, L. H., \&Aronoff, J. (2004). Dating violence among adolescents: Prevalence,gender distribution, and prevention program effectiveness. Trauma, Violence \& Abuse, 5,123-142.

Howell, D.C. (2008). The analysis of missing data.In W. Outhwaite\& S. Turner (Eds.).The SAGE Handbook of Social Science Methodology.Thousand Oaks, CA: Sage.

Ikeola, A. A., Joseph E. U., Olufunmilayo I. F. (2014) Prevalence and Correlates of Intimate Partner Violence towards University female students. BMC Women's Health.

Johnson, M.P. (2006). ConflicHt and control: Gender symmetry and asymmetry in domestic violence. Violence Against Women, 12, 1003-1018.

Josephson, W.L., \&Proulx, J.B. (2008).Violence in young adolescents' relationships.Journal of Interpersonal Violence, 23(2), 189-208.172

Katz, J., Kuffel, S.W., \&Coblentz, A. (2002). Are there gender differences in sustaining dating violence? An examination of frequency, severity, and relationship satisfaction.Journal of Family Violence, 17, $247-271$.

Kaura, S.A., \&Lohman, B.J. (2007). Dating violence victimization, relationship satisfaction, mental health problems, and acceptability of violence: A comparison of men and women. Journal of Family Violence, 22, 367-381.

Kimberg, L. (2008). Addressing intimate partner violence in male patients: A review and introduction of pilot guidelines.Journal of General Internal Medicine, 23(12),2071-2078.

McClennen, J.C., Summers, B., \& Vaughan, C. (2002). Gay men's domestic violence: Dynamics, help-seeking behaviours, and correlates. Journal of Gay and Lesbian Social Services, 14(1), 23-49.

McKelley, R.A. (2007). Men's resistance to seeking help: Using individual psychology to understand counselingreluctant men. Journal of Individual Psychology, 63(1), 48-58.

Pugh, B., Wineland, C., Dardis, T., Gidycz, C. (2011, Oct.). “I shouldn't have been drinking:” College sexual assault victims' attributions of blame and trauma symptoms. Poster session presented at the annual Meeting of the Ohio Psychological Association, Newark, OH.

Rickwood, D. (2002). Mental health help-seeking behaviour of high-school students. Invited presentation to the Legislative Assembly for the ACT Standing Committee on Health Regarding the Health of School-Age Children.August 15, Canberra City, Australia.C

Riggs, D.S.,\& O'Leary, D.K. (1996). Aggression between heterosexual dating partners: An examination of a causal model of courtship aggression. Journal of Interpersonal Violence, 11, 519-540.

Riggs, D.S., Caulfield, M.B., \& Street, A.E. (2000). Risk for domestic violence: Factors associated with perpetration and victimization. Journal of Clinical Psychology,56, 1289-1316.

Rouse, L.P., Breen, R., \& Howell, M. (1988). Abuse in intimate relationships: A comparison of married and dating college students. Journal of InterpersonalViolence, 3, 414-429.

Saunders, D.G., Lynch, A.B., Grayson, M., \& Linz, D. (1987). The inventory of beliefs about wife-beating: The construction and initial validation of a measure of beliefs and attitudes. Violence and Victims, 2, 39-57.

Seelau, S.M., \&Seelau, E.P. (2005).Gender-role stereotypes and perceptions of heterosexual, gay and lesbian domestic violence.Journal of Family Violence, 20, 363-371.

Shook, N.J., Gerrity, D.A., Jurich, J. \&Segrist, A.E. (2000). Courtship violence among college students: A comparison of verbally and physically abusive couples. Journal of Family Violence, 15, 1-22.

Shorey, R.C., Cornelius, T.L., \& Bell, K.M. (2008). A critical review of theoretical frameworks for dating violence: Comparing the dating and marital fields.Aggression and Violent Behaviour, 13, 185-194.178 
Sorenson, S.B., \& Taylor, C.A. (2005). Female aggression toward male intimate partners: An examination of social norms in a community-based sample. Psychology of Women Quarterly, 29, 79-96.

Sternberg, Robert J. (2007). "Triangulating Love".In Oord, T. J. The Altruism Reader: Selections from Writings on Love, Religion, and Science. West Conshohocken, PA: Templeton Foundation. Page 332.

Straus, M.A. (2009). Gender symmetry in partner violence: The evidence and the implications for primary prevention and treatment. In J. R. Lutzker\& D. J.Whitaker(Ed.), Prevention Of Partner Violence: Research and Evidence-Based Intervention Strategies, (pages 245-271). Washington D.C.: American Psychological Association.

Stuart, G. L., Moore, T. M., Gordon, K. C., Hellmuth, J. C., Ramsey, S. E., \&Kahler, C. W. (2006). Reasons for intimate partner violence perpetration among arrested women. Violence Against Women, 12, 609-621.

Watson (2001).Gender differences in the longitudinal predictors of adolescent dating violence. Preventive Medicine, 32, 128-141. doi:10.1006 